Ecology

\section{A niche for cyanobacteria containing chlorophyll $\boldsymbol{d}$}

- he cyanobacterium known as Acaryochloris marina is a unique phototroph that uses chlorophyll $d$ as its principal light-harvesting pigment instead of chlorophyll $a$, the form commonly found in plants, algae and other cyanobacteria; this means that it depends on far-red light for photosynthesis. Here we demonstrate photosynthetic activity in Acaryochloris-like phototrophs that live underneath minute coral-reef invertebrates (didemnid ascidians) in a shaded niche enriched in nearinfrared light. This discovery clarifies how these cyanobacteria are able to thrive as freeliving organisms in their natural habitat.

Acaryochloris marina was first isolated from extracts of didemnid ascidians ${ }^{1,2}$ and was presumed to be a symbiont, like the cyanobacterium Prochloron sp., which contains chlorophyll $a$ and $b$, and is found inside didemnids ${ }^{3}$. Acaryochloris marina has been found on red algae 4 and a free-living Acaryochloris-like organism has been discovered in a turbid saline lake ${ }^{5}$. This indicates that cyanobacteria containing chlorophyll $d$ may be fairly widespread, yet little is known about their habitat and ecology.

In a microphotometric survey of the didemnid ascidians Lissoclinum patella,
Trididemnum paracyclops, Diplosoma similis and Diplosoma virens, we investigated the occurrence and distribution of cells containing chlorophyll $d$ (for methods, see supplementary information). Prochloron, and some unicellular cyanobacteria containing chlorophyll $a$ and phycobiliproteins, colonized internal cavities of the didemnids, but we found no evidence of chlorophyll $d$ in the ascidians. However, biofilms growing on the underside of the didemnids contained clusters of pale, greenish-yellow Acaryochlorislike morphotypes: these had spectral absorption and fluorescence features that were characteristic of chlorophyll $d$ (Fig. 1a, b; and see supplementary information).

We cultured these Acaryochloris-like cells from the biofilm. Sequence analysis of the isolate (results not shown) indicates that the genes that encode cells' light-harvesting protein $(p c b C)$ and $16 \mathrm{~S}$ ribosomal RNA correspond to those of A. marina: there is $100 \%$ identity with the 302-base-pair polymerasechain-reaction fragment and 99\% identity with the 392-base-pair fragment, respectively (NCBI database $^{6}$ ).

Fibre-optic microprobe measurements ${ }^{7}$ in $D$. virens showed intense attenuation of visible light. Far-red light penetrated more efficiently through the ascidian tissue, and was enhanced relative to the incident light owing to light-trapping effects ${ }^{3,7}$. Under all ascidians, visible light was strongly depleted but there was 10-20 times more far-red light,


Figure 1 Distribution, spectral characteristics and photosynthesis of cells containing chlorophyll $d$ that are associated with the didemnid ascidian Diplosoma virens. a, Vertical section through D. virens, showing the green cells of symbiotic cyanobacterium Prochloron sp. inside cavities, and a biofilm (white) patch of Acaryochloris-like cells growing on the underside of the ascidian (scale bar, $2 \mathrm{~mm}$ ). b, Top, spectral absorbance (solid lines) and ultraviolet-excited fluorescence (dashed lines) of cells from the biofilm shown in a (red curves) and cells from an A. marina culture (blue curves). Arrow, absorption maximum of chlorophyll $d$. Data were normalized to the maximal absorbance and fluorescence, respectively. Bottom, spectral irradiance measured below $D$. virens after the biofilm had been removed, expressed as a percentage of downwelling irradiance at the tissue surface. c, d, Images as in a, but showing the maximal photosystem-\|l (PSII) quantum yield of the dark-adapted section (c) and the effective PSIl quantum yield at an irradiance of $585 \mu \mathrm{mol}$ photons $\mathrm{m}^{-2} \mathrm{~s}^{-1}$ (d). Both variables were scaled to the same colour gradient (0-1). e, PSII quantum yield (dashed lines) and relative rates of photosynthesis (solid lines) as a function of irradiance in Prochloron symbionts (green) and in Acaryochloris-like cells (red), taken from areas circled in a.

providing an ideal niche for cyanobacteria containing chlorophyll $d$, which absorbs maximally at 700-720 nm (Fig. 1b).

We used variable chlorophyll fluorescence imaging to assess photosynthesis of the cyanobacteria containing chlorophyll $d$ in their natural habitat. Maximal quantum yields of photosystem II (PSII) were 0.77 and 0.59 in zones comprising Prochloron and Acaryochloris-like cells, respectively (Fig. 1c). Maximal PSII quantum yields of $0.67-0.80$ have been reported for $A$. marina cultures ${ }^{8}$.

As expected, the quantum yield of PSII decreased with increasing irradiance (Fig. 1d). Surprisingly, the Acaryochloris-like cells were, like Prochloron, able to sustain high photosynthetic activity at strong light intensity (Fig. 1e). A similar light adaptation is also evident in A. marina 9 .

It is an apparent paradox that Acaryochloris-like cells thrive in extreme shade but show features of adaptation to strong light. This unusual photoacclimation reflects the fact that they live in an environment rich in near-infrared light and that chlorophyll $d$ is the main light-harvesting pigment that drives both photosystems I and II under these conditions ${ }^{7,10}$.

We conclude that Acaryochloris-like cyanobacteria grow in biofilms beneath didemnid ascidians, where far-red is enhanced over visible light and is used for oxygenic photosynthesis. This explains the occurrence of epiphytic $A$. marina on the underside of red algae ${ }^{4}$. Cyanobacteria that contain chlorophyll $d$ may thrive in other habitats with little visible light, but further microenvironmental controls may be important in defining the niche of these microorganisms.

Michael Kühl ${ }^{\star}$, Min Chen $\dagger$, Peter J. Ralph Ulrich Schreiber\$, Anthony W. D. Larkum $\dagger$

${ }^{*}$ Marine Biological Laboratory, Institute of Biology,

University of Copenhagen, 3000 Helsingør, Denmark e-mail:mkuhl@bi.ku.dk

$\dagger$ School of Biological Sciences, A08, University of Sydney, New South Wales 2006, Australia \$Institute for Water and Environmental Resource Management, University of Technology Sydney,

Gore Hill, New South Wales 2065, Australia

§Julius-von-Sachs-Institut für Biowissenschaften,

Universität Würzburg, 97082 Würzburg, Germany

1. Miyashita, H. et al. Nature 383, 402 (1996).

2. Miyashita, H., Ikemoto, H., Kurano, N., Miyachi, S. \&

Chihara, M. J. Phycol. 39, 1247-1253 (2003).

Kühl, M. \& Larkum, A. W. D. in Symbiosis: Mechanisms and Model Systems (ed. Seckbach, J.) 273-290 (Kluwer, Dordrecht, 2002).

4. Murakami, A., Miyashita, H., Iseki, M., Adachi, K. 8 Mimuro, M. Science 303, 1633 (2004).

Miller, S. R. et al. Proc. Natl Acad. Sci. USA 102, 850-855 (2005)

6. Chen, M., Hiller, R. G., Howe, C. J. \& Larkum, A. W. D. Mol. Biol. Evol. 22, 21-28 (2005).

Kühl, M. \& Fenchel, T. Microb. Ecol. 40, 94-103 (2000)

8. Schiller, H., Senger, H., Miyashita, H., Miyachi, S. \& Dau, H. Fed. Eur. Biochem. Soc. Lett. 410, 433-436 (1997).

9. Miyashita, H. et al. Plant Cell Physiol. 38, 274-281 (1997)

10. Boichenko, V. A., Klimov, V. V., Miyashita, H. \& Miyachi, S. Photosynth. Res. 65, 269-277 (2000).

Supplementary information accompanies this communication on Nature's website.

Competing financial interests: declared none. 